\title{
Promote Academic Satisfaction and Performance: Building Academic Resilience through Coping Strategies
}

\begin{abstract}
The aim of this article is twofold: (1) to validate the psychometric properties of the Academic Resilience Scale (AR-S) in a Spanish university context; and (2) to test a model where different coping strategies are antecedents of academic resilience, and academic satisfaction and performance are its consequences. The studies were conducted among 185 (study 1) and 780 (study 2) students. In study 1, it was analyzed construct validity, reliability, convergent and divergent validity of AR-S. The hypothesized model (study 2) was tested using structural equation modeling. The results confirmed the good psychometric properties of the AR-S in the Spanish context, giving evidence for its validity. Furthermore, the distinctive role of different coping strategies in resilience was confirmed, as well as the relationship between resilience and academic satisfaction. No direct relationship between resilience and performance was found, highlighting the full mediation role of satisfaction.
\end{abstract}

Keywords: Academic Performance; Academic Resilience; Academic Satisfaction; Coping; Scale Validation. 


\section{Promote Academic Satisfaction and Performance: Building Academic Resilience through Coping Strategies}

\section{Introduction}

In view of an increasing need for healthy and competent workers that can cope with the current dynamic and changing work context, it is crucial to educate and motivate university students in order to provide individuals who will be valuable and educated contributors to the economy and the nation in the long run (Riolli, Savicki, \& Richards, 2012). Research has shown that psychological distress among university students is significantly higher than among the general population (Stallman, 2010) and it has also been established that stress increases as students progress in their studies (Putwain, 2007). Indeed, university students confront many challenges in the pursuit of their educational goals, ranging from exams, demands of their academic course work to managing intrapersonal and interpersonal changes (Roddenberry \& Renk, 2010; Ross, Niebling, \& Heckert, 1999). Although these challenges may be considered as micro-stressors, due to their accumulated effects over time they are important for health (Zautra, 2003) and can have a variety of negative psychological and behavioral effects that may reduce students' performance. For instance, academic stress has been associated with disorders such as depression (Dao, Lee, \& Chang, 2007), school failure (McDonald, 2001), study burnout (Salanova, Schaufeli, Martínez, \& Bresó, 2010), and disturbances in the immune system (Vedhara \& Nott, 1996).

However, some students have the capacity to successfully withstand the consequences of negative academic experiences. They are easily encouraged following minor setbacks and generally view negative challenging events as surmountable (e.g., Struthers \& Perry, 1996). Nevertheless, little is known about the relative strength of various factors that promote positive adaptation in the face of academic stress (Leary \& DeRosier, 2012). The concept of 
resilience might help to explain why some individuals who experience high levels of stress are able to withstand it and may even thrive on it, thereby enabling them to manage future challenges effectively (Grant \& Kinman, 2012). Thus, to account for the discrepancy in students' responses to negative events, the present study focused on Academic Resilience (AR) as the factor that promotes positive adaptation and outcomes during the academic stage.

From a stress-coping perspective, numerous studies have highlighted the importance of coping when dealing with adversity (e.g., Clauss-Ehlers, 2008; Leipold \& Greve, 2009), and individuals use a range of coping strategies to deal with that. Therefore, in academicrelated stressful situations, students may have different ways to face it, that is, they possess different coping strategies, the results of which will differ in their effects on well-being and performance. In this study we investigated the predicting role of distinct coping strategies on AR. Moreover, we examine whether the relationship between coping strategies and AR stimulated positive academic outcomes, assessed by two widely recognized indicators, namely, academic satisfaction and performance. In sum this study aims to further our understanding about how coping strategies drive the individual experience to promote resilience in order to obtain more satisfaction and better performance.

The strengths of this study are based on the extension of previous research in this field in several ways. First, a validation in Spanish context of an AR scale is proposed in order to have a reliable instrument to measure resilience and test for its antecedents and outcomes. Second, although earlier studies have already examined coping strategies as predictors of resilience, they mainly combine scales into general problem- and emotion-focused categories of coping. Instead, as suggested by Carver, Scheier, and Weintraub (1989), we use the data to determine the composition of the higher-order factors because different samples exhibit different patterns of relations. Third, we include the Grade Point Average (GPA) provided by the University as an objective measure of academic performance in order to have an objective 
evaluation of this variable and better control for method bias, thus strengthening the validity of our results. Moreover, the measure of academic performance (GPA) was taken 4 or 5 months after the administration of the questionnaire with the psychosocial variables, thus studying the effect of psychosocial variables on performance over time. Finally, we use a sample of students pursuing different degree courses at different faculties in order to reinforce the generalizability of the results.

\section{About the concept and measure of academic resilience}

It has been argued that focusing on salutogenic (or health-enhancing) rather than pathogenic (or disease-reducing) factors will be more successful in promoting well-being in various life contexts (Seligman, 2003). In accordance with this framework, in this study we focused on resilience, since it refers to the process of positive adaptation in the face of stress or adversity (Luthar, Cicchetti, \& Becker, 2000). Applied to the academic context, resilience research focuses on the mechanisms and the interactive processes that enable students to succeed despite unfavorable circumstances (Doll \& Lyon, 1998). We refer to AR as the process of dealing with academic adversity and achieving positive outcomes in stressful situations. A substantial body of evidence reports that resilient students are those who sustain high levels of achievement motivation and performance despite the presence of stressful events and conditions (Leary \& De Rosier, 2012). To date, the few studies that have dealt with AR are focused on ethnic-minority groups, learning difficulties, and extreme underachievers. However, AR is relevant to all students because at some point all of them may experience challenges during their academic life (Martin \& Marsh, 2006). Consequently, we propose that the study of AR can help further our understanding of the process through which students are able to successfully adapt to and "bounce back" from stressing situations, as well as providing insight into possible interventions (Steinhardt \& Dolbier, 2008). 
It is interesting to notice that over the last few years different instruments have been used to measure resilience in student populations; however, in most cases they are not specific for the academic context (e.g., Campbell-Sills, Stein, \& Murray, 2006; Dolbier, Jaggars, \& Steinhardt, 2010). To our knowledge the scale proposed by Martin and Marsh (2006) is the only one that: (a) focuses specifically on AR, and (b) has a different content from previous measures, which have generally assessed protective factors or resources involving personal characteristics (e.g., Connor \& Davidson, 2003), and framed items as statements referring to the process of bouncing back, adapting to stress, or thriving in the face of academic adversity. Thus, we aim to evaluate the psychometric characteristics of the Spanish version of the AR-S of Martin and Marsh (2006) in the first study in this paper (see study 1). Once it was confirmed that AR-S is a reliable scale to measure AR in Spanish context, it can be used as measure of resilience in order to test antecedents and outcomes.

\section{Coping strategies as antecedents of academic resilience}

To understand people who positively face adversity, it is undoubtedly important to identify the factors that may promote resilience, such as coping strategies (Smith et al., 2008; Steinhardt \& Dolbier, 2008). Coping has been defined as a person's efforts to remove, reduce, or manage threatening events or situations that are appraised as challenging or stressful (Lazarus \& Folkman, 1984). Although resilience and coping are sometimes used interchangeably, they are in fact related but conceptually distinct constructs. The distinction between AR and coping strategies is based on the definition of the constructs: whereas coping refers to the set of cognitive and behavioural strategies used by an individual to manage the demands of stressful situations, resilience refers to adaptive outcomes in the face of adversity (Campbell-Sills et al., 2006).

Researchers have generally clustered coping responses into theoretically derived factors. One of the earlier nomenclatures (Folkman \& Lazarus, 1980), distinguishes two 
major functions of coping: problem-focused coping and emotion-focused coping. Problemfocused coping involves addressing the problem causing distress. Effective problem-focused coping probably contributes to positive psychological states by allowing people to experience some personal control and sense of accomplishment. Emotion-focused coping is aimed at regulating distress and negative emotion rather than at changing the events themselves, through the use of strategies such as escape-avoidance or support seeking. These strategies involve thoughts and/or actions that relieve or lessen the emotional impact of stress. Research has found that people who cope with stress by seeking social support or venting feelings (emotion-focused) experience more negative outcomes than do people who address the experienced stressor directly by working on solving their problems (problem-focused) (Suldo, Shaunessy, Michalowski, \& Shaffer, 2008). Previous results about coping strategies and resilience also confirmed these results (Campbell-Sills et al., 2006).

Research found that the problem-focused and emotion-focused distinction was a good starting point, but they identified meaning-focused coping as a different type of coping in which cognitive strategies are used to manage the meaning of a situation (Folkman \& Moskowitz, 2004). Meaning-focused coping is substantially aimed at regulating positive emotions. There is substantial evidence suggesting that positive emotions occur alongside negative emotions throughout intensely stressful periods and are of great significance for adaptation (Folkman, 2008). Therefore, positive emotions need to be included to learn more about how people generate and sustain them and to explore their adaptation significance in relation to outcomes.

In accordance with these three different kinds of coping categories, we postulate distinct hypotheses about the relation between coping strategies and resilience. First, we propose that students that show high levels of active coping and use problem-focused strategies are more resilient. Second, we suggest that students using emotion-focused 
strategies, which are aimed at regulating distress and negative emotions, reduce their efforts in dealing with the problem and thus are less resilient. Finally, we propose that students who regulate positive emotions by attributing meaning to the situation broaden their thoughtaction repertoires and build resources that enable them to cope and manage things effectively, like resilience.

\section{Consequences of academic resilience (satisfaction and performance)}

In studying the consequences of $\mathrm{AR}$, we focused on academic satisfaction and academic performance. In this study, academic satisfaction is considered as students' cognitive evaluations of various aspects of their academic context (i.e., teachers, degree, and faculty). Academic satisfaction was considered as the subjective intrinsic gratification students experience through their educational pursuits (Ryan, 2001), and its importance as an indicator of school adjustment (Baker, Dilly, Aupperlee, \& Patil, 2003) as well as of quality in higher education (Byrne \& Flood, 2003) is recognized. On the grounds that AR is useful in helping students to overcome the stress in the academic context, we propose that, when students show a high level of resilience, they will experience higher satisfaction with the aspects of their academic context. Indeed, students with higher levels of resilience, even when they experience adverse events in their academic context, are expected to positively adapt to and successfully bounce back from these events (Leary \& DeRosier, 2012). Therefore, we postulated that this positive response enhances their academic satisfaction.

Previous research has suggested that AR leads to an increase in academic performance (Kwok, Hughes, \& Wen, 2007), because it better prepares individuals to rebound or bounce back from adversities, problems, and failures since they are more flexible to changing demands and they tend to use setbacks as "springboards" or opportunities for growth (Tugade $\&$ Fredrickson, 2004). However, we expect resilience to influence academic performance also through satisfaction. Specifically, we propose that, when resilience is high, students will also 
perform better because they experience more academic satisfaction engendered by resilience. Previous evidence showed that attitudes are proximal antecedents and guidelines of behavior (Ajzen \& Fishbein, 2005), and it was long assumed that a cognitive attitude (i.e., satisfaction) is the primary source of student performance (Chambel \& Curral, 2005; Rode et al., 2005). Hence, we argue that academic satisfaction is a partial mediator of the effects of AR upon academic performance.

\section{STUDY 1}

The first study assessed the psychometric properties of a Spanish adaptation of the Academic Resilience Scale (AR-S) developed by Martin and Marsh (2006). We conducted a number of tests in order to determine the validity and reliability of the measure. First, a confirmatory factor analysis was carried out and construct validity was tested. Subsequently, the reliability of the AR-S was investigated, together with its convergent and divergent validity. Thus, we predict:

\section{Hypothesis 1. The Spanish version of the AR-S will demonstrate acceptable} psychometric properties (i.e., validity and reliability).

\section{Method}

\section{Sample and procedures}

The first study involved 185 students from a Spanish university. The sample size fits all the criteria suggested by Muthén and Muthén (2002) for determining sample size though a Monte Carlo study: a) parameter and standard error biases did not exceed $10 \%$ for any parameter in the model; b) the standard error bias for parameters that are the specific focus of the power analysis (e.g., the factor covariance of resilience and self-efficacy) did not exceed $5 \%$; and c) coverage, that is, the confidence intervals, was between .91 and .98. In addition to these criteria, appropriate sample size was determined because the power of the salient model parameters was above .80 . 
Participants (57.5\% females) were stratified and belonged to the four faculties of the University, that is: Faculty of Humanities and Social Sciences (56.5\%), School of Technology and Experimental Sciences (17.4\%), Faculty of Health Sciences (14.7\%), and Faculty of Law and Economics (11.4\%). Ages ranged from 18 to 44 years $(\mathrm{M}=22.8 ; \mathrm{SD}=$ 5.06 years). Most of them (95.6\%) were doing a bachelor's degree lasting four years, whereas the others were doing five-year degrees from the previous curriculum (4.4\%). Regarding the course they were doing, $13.7 \%$ were in the first year, $50.5 \%$ in the second, $27.5 \%$ in the third, $7.1 \%$ in the fourth, and $1.1 \%$ were in their fifth year. Eighty percent of them were not working at that moment.

The data were collected through a paper and pencil questionnaire which includes all the study variables. Students received a brief presentation of the study by the researchers during class time, and they were invited to individually fill out a questionnaire. In the front page of the questionnaire, they read and signed an individual informed consent. The data collected by questionnaire and the data of academic performance (GPA provided by University) were matched trough the National Identity document of each student.

\section{Measures}

All the items of measures used were scored on a 7-point scale ranging from 0 (completely disagree) to 6 (completely agree). In the questionnaire, the order of the items for the four measures was alternated.

\section{The Academic Resilience Scale.}

The Spanish version of the AR-S was a translation of the Martin and Marsh (2006) scale. It is one-dimensional and includes 6-items, each of them framed in a positive sense. An example item is: "I think I'm good at dealing with schoolwork pressures". The academic resilience score was obtained computing the mean of the 6 items that compose the scale. The original alpha for this scale was .89 (Martin \& Marsh, 2006). The translation was performed 
by two researchers, who were fluent in Spanish and English, and then two other researchers were asked to compare the Spanish and the English versions of the scale.

\section{Other measures.}

A number of existing measures were used in this study in order to assess the convergent, divergent and construct validity of the AR-S. For each of them, the score was obtained computing the mean of the items that make up each scale.

Resilience. Another measure of resilience was assessed with the short 12-item version of the Psychological Capital Questionnaire (PCQ-12, see Luthans, Avey, Smith, \& Li, 2008) adapted to the academic context. In this instrument, resilience was measured with a threeitem scale. An example item is: "I usually take stressful things in my stride with regard to my studies". Cronbach's alpha was .60.

Self-efficacy. It was measured with a five-item scale developed by Midgley and colleagues (2000) and used with a sample of Spanish students (Salanova, Bresó, \& Schaufeli, 2005). An example item is: "I can do even the hardest work in this class if I try". Cronbach's alpha was .74.

Proving Goal Orientation. Proving goal orientation was assessed with a four-item scale from the Goal Orientation scale developed by VandeWalle (1997). An example item is: "It's important for me to prove that I am better than others in class". Cronbach's alpha was .75 .

\section{Results}

\section{Construct validity}

With the purpose of confirming the one-factor structure of the AR-S and its relatedness to other constructs, we performed a confirmatory factor analysis including a theoretically relevant concept, that is to say, self-efficacy. From a theoretical point of view, self-efficacy has been advanced as an important supportive characteristic of AR. Bandura 
(2011) suggested that people high in self-efficacy view impediments as surmountable by developing requited competencies and making a perseverant effort, and thus they are able to face difficulties and remain resilient to adversity. In this way, it is proposed that students' beliefs about themselves and their academic capacities influence their behaviors and emotional reactions, thereby allowing them to perform successfully in the face of obstacles or adverse experiences.

In order to shed more light on the relationship between these variables, structural equation modeling (SEM) was used to test the fit of the structural models. The analysis was performed using AMOS 21.0 and a number of fit indices were used to assess the model fit. Goodness of fit can be determined with the following indices (Hu \& Bentler, 1999): chisquare test $(\chi 2)$; Comparative Fit Index (CFI $\geq .90)$; the Normed Fit Index (NFI $\geq .90)$; the Tucker-Lewis Index (TLI $\geq .90$ ); and Root-Mean-Square Errors of Approximation (RMSEA $\leq .08$ ). SEM results were used to compare a single-factor model (that tested all items of resilience and self-efficacy loading on one factor) with a two-factor model (that tested all items loading on two different factors) to determine which models fit better. Confirmatory factor analyses (CFA) conducted on the single-factor model revealed inadequate fit indices $\left(\chi^{2}(44)=248.59, \mathrm{CFI}=.76, \mathrm{NFI}=.73, \mathrm{TLI}=.64, \mathrm{RMSEA}=.16\right)$, whereas the two-factor model fits the data well $\left(\chi^{2}(43)=90.03, \mathrm{CFI}=.95, \mathrm{NFI}=.90, \mathrm{TLI}=.92, \mathrm{RMSEA}=.08\right)$. The comparison of chi-square statistics indicated that the two-factor model fits the data significantly better than did the one-factor model $\left(\Delta \chi^{2}(1)=158.56, p<.001\right)$. All items had significant loadings on their intended latent factor. Moreover, as expected, self-efficacy related positively and significantly to AR: $\beta=.37, p<.001$. Based on these findings, we can empirically confirm the factor structure of the resilience measure and also that self-efficacy relates significantly to AR, but they are conceptualized in different ways, thus providing empirical support for the construct validity of AR-S. 


\section{Reliability}

An important step in establishing the psychometric characteristics of a scale is to determine its reliability. We used Cronbach's alpha as a measure of the internal consistency reliability of the scale, because it reflects the extent to which the items are homogeneous. The AR-S showed excellent Cronbach's $\alpha=.90$ (Kline, 2011).

\section{Convergent validity}

Convergent validity of the scale was checked in two ways. Firstly, we inspected whether our measures of AR were related with another (criterion) resilience measure. The convergent validity of the AR-S was examined by correlating it with the resilience scale from the PCQ-12, adapted to the academic context (Luthans et al., 2008; Luthans, Youssef, Sweetman, \& Harms, 2013). Convergent validity is assumed when the scales of the tested instrument correlate both positively and moderately to highly with the criterion instrument (Kline, 2011). Pearson's correlation coefficient between the AR-S and the resilience scale from the PCQ-12 was computed, and the results showed that the correlation was high and significant $(\mathrm{r}=.58, p<.01)$.

We then computed the average variance extracted (AVE; Fornell \& Larcker, 1981). The AVE represents the extent to which items of a specific construct "converge" or share a high proportion of variance in common. A model can be considered to have good convergent validity if at least $50 \%$ of the measurement variance is captured by the construct (AVE $>.50$ ). The estimated AVE of the AR-S is .61. Taken together, results support the convergent validity of the AR-S.

\section{Divergent validity}

Finally, the divergent validity was checked by demonstrating that AR is different from another (criterion) variable. We investigated the divergent validity of the AR-S by correlating it with the proving dimension of goal orientation. A proving goal orientation is a focus on 
demonstrating one's competence and the gaining of favorable judgments or positive evaluations from others (VandeWalle et al., 2001). Previous evidence showed that proving goal-oriented students typically do not increase their efforts following failures and, when confronted with obstacles, they exhibit decreased problem-solving, and readily disengage from goals even if they were performing adequately previously (Snyder et al., 2002). Thus, they are not expected to develop resilience when faced with an adverse situation.

Divergent validity is assumed when the scales of the tested instrument show a low-tomoderate correlation with the criterion instrument (Kline, 2011). Pearson's correlation coefficient between the AR-S and the proving goal orientation scale was computed and the results showed that the correlations were not significant $(\mathrm{r}=-.01, p=.95)$. These results provide evidence for a good divergent validity of the AR-S.

\section{STUDY 2}

In the second study, the hypothesized model was explored through the following hypotheses:

Hypothesis 2. Problem-focused coping will be positively related with academic resilience.

Hypothesis 3. Emotion-focused coping will be negatively related with academic resilience.

Hypothesis 4. Meaning-focused coping will be positively related with academic resilience.

Hypothesis 5. Academic resilience will be positively related with academic satisfaction.

Hypothesis 6. Academic satisfaction will partially mediate the relationship between academic resilience and performance.

\section{Method}




\section{Sample and procedures}

The second study involved 780 university students from a Spanish university. The sample size is adequate to carry out the proposed analyses since 780 subjects participated in the study and exceeded the minimum of 754 observations needed for a statistical power of .80 and eight degrees of freedom (MacCallum, Browne, \& Sugawara, 1996), which are the degrees of freedom of our proposed model.

Participants (59.7\% females) were stratified and belonged to the four faculties of the University, namely: Faculty of Humanities and Social Sciences (33.2\%), School of Technology and Experimental Sciences (25\%), Faculty of Law and Economics (24.5\%), and Faculty of Health Sciences (17.3\%). Ages ranged from 18 to 61 years $(M=22.7 ; \mathrm{SD}=5.68$ years). Most of them (93.4\%) were doing a bachelor's degree lasting four years, whereas the others were doing five-year degrees from the previous curriculum $(6.6 \%)$. Regarding the year they were studying, $35.7 \%$ were in the first, $37.2 \%$ were in the second, $19.6 \%$ were in the third, $6.5 \%$ were in the fourth, and $9 \%$ were in their fifth year. The $84.1 \%$ of them were not working at that time.

The data were collected through a paper and pencil questionnaire which includes all the study variables. Students received a brief presentation of the study by the researchers during class time, and they were invited to individually fill out a questionnaire. In the front page of the questionnaire, they read and signed an individual informed consent. The data collected by questionnaire and the data of academic performance (GPA provided by University) were matched trough the National Identity document of each student.

\section{Measures}

The students completed the AR-S described in Study 1 to assess their resilience. Moreover, three other measures were used in this study in order to test our hypotheses. 
Coping strategies. The Spanish version of the Brief COPE inventory was used to assess coping strategies (Perczek, Carver, Price, \& Pozo-Kaderman, 2000). It includes 14 two-item subscales: active coping, acceptance, emotional support, instrumental support, positive reframing, planning, self-distraction, denial, behavioral disengagement, venting, selfblame, religion, humor, and substance use. An example item is: "In the presence of difficult situations related to my studies, I've been taking action to try to make the situation better" (active coping subscale). For each of the items, respondents indicated the extent to which they used the strategy in dealing with stressful situations on a 4-point Likert scale ranging from 0 (not at all) to 3 (a lot). Cronbach's alphas ranged between .62 and .94 (mean $=.77$ ). The order of the coping strategies items was alternated between different subscales.

Academic Satisfaction. Academic satisfaction was measured with a three-item scale (Salanova et al., 2005) that takes into consideration three salient aspects: their professors, the degree that they are studying for, and the faculty to which they belong. An example item is: "How satisfied are you with your professors?" and students indicated the extent of their satisfaction on a 5-point Face scale ranging from 1 (frowning) to 5 (smiling) and academic satisfaction score was obtained computing the mean of the three items.

Academic success. It was assessed by using objective performance as reflected by the GPA, provided by the University at the end of the exam session after the distribution of the questionnaire, which therefore means 4-5 months later. In accordance with the Spanish system of qualifications, GPA ranged from 5 (poor) to 10 (excellent).

\section{Fit indices}

Our data were analyzed by means of SEM techniques using the AMOS 21.0 (Arbuckle, 2005). The covariance matrix was analyzed using the maximum-likelihood estimation method. To reduce the complexity of the models examined, we used manifest variables for all constructs (Jöreskog \& Sörbom, 1993). To use scores for our coping manifest 
variables that encapsulate the factor loadings of their underlying subscales, we calculated their weighted factor score. Since AR, satisfaction, and GPA are one-dimensional constructs, we used their standardized scores as manifest variables (Xanthopoulou, Bakker, Demerouti, \& Schaufeli, 2009). Goodness of fit was determined as in Study 1.

\section{Results}

\section{Preliminary analyses}

Before testing our hypotheses, we conducted an exploratory factor analysis (EFA) to examine how the coping subscales grouped together to form broader coping constructs in university students. In fact, the theory proposes that the 14 coping strategies assessed by these subscales are part of several larger constructs (e.g., problem-focused, emotion-focused, meaning-focused); however, researchers have warned against the practice of assuming that certain coping strategies are always grouped in the same way across different contexts (Lazarus \& Folkman, 1984). Therefore, we standardized the total score of each lower-order coping subscale and conducted a principal axis factoring (PAF) analysis with varimax rotation on the 14 coping subscales. The advantage of PAF is that it takes into account the degree to which each lower-order factor contributes to the overall factor (i.e., factor loadings), when calculating factor scores (Xanthopoulou et al., 2009). Subscales with a loading of less than .40 (self-blame, religion, substance use, and self-distraction) were sequentially deleted, which resulted in 10 subscales loading on 4 factors. Factor loadings of the lower-order coping subscales are presented in Table 1. Factor 1 included the subscales planning and active coping, named problem-solving coping. Factor 2 consisted of the subscales emotional support, instrumental support, and venting, named social coping. Factor 3 consisted of the subscales denial and behavioral disengagement, named avoidant coping. Factor 4 included the subscales positive reframing, humor and acceptance, referred to as positive acceptance coping. All 4 factors accounted for $45.03 \%$ of the total variance 
explained. In accordance with the coping literature, factor 1 (problem-solving coping) is consistent with the problem-focused category, factors 2 and 3 (social and avoidant coping) are representative of the emotion-focused category, and factor 4 (positive acceptance coping) is coherent with the meaning-focused category.

\section{PLEASE INSERT TABLE 1 ABOUT HERE}

In order to confirm the structure of our coping factors, we also conducted a series of subscale-level CFA. We compared a model where the 14 original subscales from COPE load on one general coping factor (M1) with a model where the final 10 subscales from the EFA load on one general coping factor (M2), and with a model where the final 10 subscales from the EFA load on the respective underlying covariate factors (M3). Results supported the use of 10 subscales of coping against the 14 originally proposed $\left(\Delta \chi^{2} \mathrm{M} 1-\mathrm{M} 2(42)=243.80, \mathrm{p}<\right.$ $.001)$, and also their belonging to the four factors $\left(\Delta \chi^{2} \mathrm{M} 2-\mathrm{M} 3(6)=553.28, \mathrm{p}<.001\right)$.

\section{Descriptive analyses}

Table 2 presents the correlations among the study variables, as well as Cronbach's $\alpha$ on the diagonal. Given that the variables used are standardized factor scores, means and standard deviations are not reported. Correlations between the 10 separate subscales of coping will be provided by the first author upon request.

\section{PLEASE INSERT TABLE 2 ABOUT HERE}

In order to mitigate problems with common method bias, we implemented two procedural remedies as suggested in Podsakoff, MacKenzie, and Podsakoff (2012). First, we obtained the measures from different sources, specifically the predictor and mediator measures from students and the criterion measure from an objective source. Second, we differentiated the scale properties shared by the measures of the predictor and mediator variables. Finally, the correlations between the study variables were examined, and no significant relationships were found between some of them. When common method bias is 
present, all of the relationships should be significant; otherwise the common method bias is so small that it is meaningless (Spector, 2006).

\section{Test of hypotheses: path analyses}

When model was tested, social and avoidant coping did negatively and significantly predict resilience $(\beta=-.25, p<.001$, and $\beta=-.17, p<.001$, respectively), whereas problemsolving and positive acceptance coping positively and significantly predicted resilience $(\beta=$ $.20, p<.001$, and $\beta=.34, p<.001$, respectively). Resilience positively and significantly predicted satisfaction $(\beta=.16, p<.001)$, which in turn positively and significantly predicted GPA $(\beta=.14, p<.001)$. No significant relationship was found between resilience and GPA $(\beta=.01, p=.933)$, which suggests full mediation by satisfaction. The results of Sobel test suggest confirmed the fully mediated the relationship $(\mathrm{z}=2.99, p<.01)$. However, our hypothesized model (M1) showed a poor fit to the data: $\chi^{2}(8)=60.85$, RMSEA $=.09, \mathrm{NFI}=$ $.82, \mathrm{IFI}=.84$ and $\mathrm{CFI}=.83$.

The so-called modification indices indicated that the fit of the model could be improved significantly by including direct paths from problem-solving coping to academic satisfaction and GPA, as well as a direct path from social coping to GPA. The results of the SEM analyses showed that the modified model (M2) fits the data reasonably well, $\chi^{2}(6)=$ $16.15, \mathrm{RMSEA}=.05, \mathrm{NFI}=.95, \mathrm{IFI}=.97$, and $\mathrm{CFI}=.97 . \mathrm{M} 1$ and $\mathrm{M} 2$ were compared using the chi-square difference test, and results supported the modified model $\left(\Delta \chi^{2}{ }_{\mathrm{M} 1-\mathrm{M} 2}(3)=44.7\right.$, $p<.001)$. The relationships between the variables are almost invariant between M1 and M2, but the inclusion of these three paths significantly improved the model. Moreover, these additional relationships in M2 were significant, thereby showing that problem-solving coping has a direct impact on academic satisfaction and that both problem-solving and social coping have a direct impact on GPA. Figure 1 shows the final model, with the standardized coefficients. 


\section{PLEASE INSERT FIGURE 1 ABOUT HERE}

\section{Discussion}

The lack of specific tools for measuring resilience in academic contexts in Spain requires the validation of suitable instruments for studying AR. These instruments allow resilience to be evaluated and also enable it to be related to other variables. In this sense, the purpose of the present study was twofold: i) to evaluate the psychometric characteristics of the AR-S of Martin and Marsh (2006) in the Spanish context, checking for its validity and

reliability, and ii) to investigate the relationships between coping strategies, AR and academic satisfaction, as well as the impact on academic performance over time. To achieve these objectives, we conducted two studies. The findings of the first study suggest that the Spanish version of the AR-S demonstrated acceptable psychometric properties. Regarding the second study, the results revealed that students who used emotion-focused coping strategies showed less AR, whereas resilience was higher when problem- and meaning-focused coping strategies were used. Moreover, students with a high level of AR tended to be more satisfied with their academic context and students who displayed more satisfaction tended to perform better over time. Furthermore, results indicated that AR was only indirectly related to performance through satisfaction. Finally, the study revealed three unpredicted significant paths that link coping strategies with outcomes, namely problem-solving coping to both academic satisfaction and performance, and social coping to academic performance.

\section{Theoretical contributions}

The present study represents a step forward with respect to previous research into AR in several ways. Firstly, the validation of the Spanish version of the AR-S from Martin and Marsh (2006) was successful. In order to provide solid evidence for the psychometric characteristics of the scale, we carried out a number of analyses rigorously following wellestablished validation procedures, and we can conclude that the Spanish version of the AR-S 
demonstrated good psychometric properties. A contribution of the study is the usage of a heterogeneous sample, hence the Spanish translation of the AR-S may be used by scholars as a valid scale to investigate resilience in the academic context.

Secondly, we advance theoretical understanding of how different kinds of coping strategies are related with AR. One strength of the current study is that we factor analyzed the subscales to allow student responses to determine subscale categorization. However, the factors found in this study are strongly supported by previous theoretical conceptualization (Folkman \& Moskowitz, 2004), thus giving support to the validity of our categories. Specifically, we have identified two coping strategies, namely problem-solving and positive acceptance, which are positive related with resilience. Within the academic context, problemsolving coping should assist students in adjusting to the many challenges posed by the environment, because it involves taking active steps to alter the circumstances or address the problem. Therefore, students who tend to change the situation when they are faced with stressful events have higher levels of resilience. Positive acceptance coping underlies the cognitive strategies used to manage the meaning of a situation and to regulate positive emotions, which is consistent with the emerging focus on meaning-focused coping (Folkman, 2008). In turn, meaning-focused coping is said to generate positive emotions and the underlying appraisals, and these emotions and appraisals influence the resilience process. Therefore, students who tend to generate positive emotions by attributing meaning to the situation show higher resilience. In contrast, we have identified two coping strategies, namely social and avoidance coping, which are negatively related with resilience. Both strategies belong to the traditional emotion-focused category and are centered on the regulation of negative emotions, although each of them refers to a definite variety of strategies. Focusing on social coping, students center on looking for social support and venting emotions. Although the strategy can at first help to reduce stress, symptom reduction can be 
dysfunctional if students mentally focus too much on the situation that created the stress when venting. Therefore, students using more social coping strategies show lower resilience. Finally, avoidance is a coping strategy occurring when students try to ignore a stressful situation by not thinking about it. Ignoring a stressful situation can be positive in that it may reduce stress, but avoiding the reality of a stressful situation can allow the situation to worsen, thus increasing stress in the long run (Belanger, Lewis, Kasper, Smith, \& Harrington, 2007). Hence, students who tend to avoid the problem have lower level of resilience.

Thirdly, in studying the positive outcomes of AR, we further extend current theory in at least two ways. On the one hand, past research on resilience outcomes focused predominantly on successful performance as an indicator of positive adjustment. However, students' attitudes and beliefs are more proximal outcomes (Baker et al., 2003) and may be better able to predict eventual academic-related behaviors, such as performance. Thus, in this research, we included academic satisfaction as a measure of positive academic outcomes and found that $\mathrm{AR}$ is positively related with satisfaction. The role of AR in predicting satisfaction seems particularly encouraging, as it suggests that a higher level of resilience is associated with increased satisfaction with their academic context. On the other hand, in contrast to our expectations, we found that resilience is associated to performance only via satisfaction. Although further investigation is needed, this result seems to turn about the recognized statement that higher resilience is a predictor of better performance (Luthar, 1991). Some possible explanations can be provided to explain this unexpected result. While resilience may influence academic performance, so do many other circumstances and student characteristics, such as performance self-efficacy, grade goal, and effort regulation (Ouweneel, Schaufeli, \& Le Blanc, 2013; Richardson, Abraham, \& Bond, 2012). Moreover, AR might not have a direct impact on performance because the process of bouncing back is not necessarily directly related to an increase in performance. In fact it would be if there was a psychological process 
engendered by resilience that - through an increase in attitudes (i.e., satisfaction) - affects performance.

Finally, unexpected results revealed the direct effects of the selected coping strategies on outcomes. Specifically, we found a direct relationship that links problem-solving coping with both academic satisfaction and performance, thereby providing evidence that the cumulative effect of using problem-solving strategies across a range of stressful situations results in better outcomes. Because problem-solving coping involves strategies to alter or diminish a stressful event, it seems plausible that it is positively related with satisfaction and performance. For instance, if the stressor is an impending assignment, focusing on the assignment should result in getting the assignment handed in on time, and getting a good grade (MacCann, Fogarty, Zeidner, \& Roberts, 2011). Furthermore, we found a direct relationship between social coping and performance. There are several possible pathways by which social coping strategies may influence academic performance. First, students who are able to regulate their negative emotions through venting or support seeking could be less impaired in assessment and learning situations. Second, in the Spanish context, academic performance requires not just passing examinations, but calls for collaboration and teamwork, for instance in the form of group projects (Ahles \& Bosworth, 2004). Social coping has been linked with better social relationships, suggesting that individuals using this kind of coping could be better able to maintain the social relationships required for effective group work, and in this way achieve higher grades (MacCann et al., 2011).

\section{Practical implications}

In terms of practical implications, we may conclude that the AR-S is a valid and reliable instrument for measuring resilience in the Spanish academic context. Additionally, this questionnaire contains only 6 items to measure resilience and is therefore a short and 
practical instrument. The AR-S can thus be considered a solid tool for conducting research on AR.

Another important point underpinning the present study concerns the proposition that both coping strategies and AR can be influenced in a direct way. Thus, the practical implication of the study is that in the university context, both coping strategies and resilience can be taken as tools to boost students' outcomes, especially for those who are underperformers or low on satisfaction. Given that our results suggest that AR is enhanced by specific coping strategies, interventions aimed at encouraging problem-solving and positive acceptance coping strategies seem to be crucial. In this regard, there are several interventions that are usually designed to teach individuals how to cope with adversity. They typically include techniques that help the individual to deal with and to handle stress (see MacCann et al., 2011).

Moreover, evidence showed that resilience can also be developed through interventions. For example, repeated exposure to positive emotions may help to strengthen an individual's resilience capacity (Fredrickson, Tugade, Waugh, \& Larkin, 2003). Specifically, positive emotions may take the form of laughter or smiles and such emotions may reinforce or strengthen resilience (Bonanno, Noll, Putnam, O’Neill, \& Tickett, 2003). Though these types of positive emotions seem simplistic, their effects may be important. Taken together, these guidelines suggest that coping and resilience could be modifiable and doing so may lead to enhanced positive academic outcomes.

\section{Limitations and research directions}

This study has several limitations which highlight important avenues for future research. With the exception of academic performance rates (i.e., GPA), perhaps the clearest limitation is the use of self-reported data, which increases the risk of common method bias (Podsakoff, MacKenzie, Lee, \& Podsakoff, 2003). Although we consider that the use of self- 
reports could be justified by the nature of the constructs, because the students are the most accurate source of their own strategies and feelings or attitudes, it introduces the possibility of response acquiescence and precludes discussion of causality. We tried to minimize such errors by differentiating the response scales for each of these variables, as suggested in Podsakoff, MacKenzie, and Podsakoff (2012).

Another limitation of the present study is that data are cross-sectional, with the exception of the GPA, which is collected at a different point in time. Although SEM analysis gives some information about the possible direction of the relationships, cross-sectional study designs do not allow one to draw firm conclusions regarding the causal ordering among the variables studied. Clearly there is a need for longitudinal studies that may allow stronger causal inferences to be made about the relationship between coping strategies, resilience, and a range of academic outcomes.

In addition, although the sample came from four different faculties and several degrees, our results are based on a sample from the same university. Thus, the results need to be replicated in order to allow our findings to be generalized to different academic contexts.

\section{Conclusions}

Although research on AR is usually focused on students who encountered greater adversity, it is important to recognize its importance for university students as a whole, because all of them have to deal with adverse and stressful situations during their academic experience. The results of the current study imply that the Spanish translation of the AR-S can be used in a valid and reliable way to measure AR. This measure may thus be used to investigate the relationship of AR with relevant antecedents and outcomes. In this sense, our results offer new insights into how university students can benefit from using adequate coping strategies in order to support the development of their resilience and to achieve positive outcomes, such as satisfaction and performance. These findings hold implications for 
researchers investigating the processes students use to deal with everyday setbacks, as well as for practitioners seeking to assist students in dealing with the highs and lows that characterize academic life. 


\section{References}

Ahles, C. B., \& Bosworth, C. C. (2004). The perception and reality of student and workplace teams. Journalism \& Mass Communication Educator, 59, 41-59.

Ajzen, I., \& Fishbein, M. (2005). The influence of attitudes on behavior. In D. Albarracín, B. T. Johnson, \& M. P. Zanna (Eds.), The handbook of attitudes (pp. 173-221). Mahwah, NJ: Erlbaum.

Arbuckle, J. L. (2005). Amos 6.0 User's Guide. Chicago, IL: SPSS Inc.

Baker, J. A., Dilly, L. J., Aupperlee, J. L., \& Patil, S. A. (2003). The developmental context of school satisfaction: Schools as psychologically healthy environments. School Psychology Quarterly, 18, 206-221.

Bandura, A. (2011). A Social Cognitive perspective on Positive Psychology. Revista de Psicología Social, 26, 7-20.

Belanger, F., Lewis, T., Kasper, G. M., Smith, W. J., \& Harrington, K. V. (2007). Are Computing Students Different? An Analysis of Coping Strategies and Emotional Intelligence. IEEE Transactions on Education, 50, 188-196.

Browne, M. W., \& Cudeck, R. (1993). Alternative ways of assessing model filt. In K. A. Bollen\& J. S. Long (Eds.), Testing structural equations models (pp. 136-162). Newbury Park, CA: Sage.

Bonanno, G. A., Noll, J. G., Putnam, F. W., O’Neill, M., \& Trickett, P. K. (2003). Predicting the Willingness to Disclose Childhood Sexual Abuse from Measures of Repressive Coping and Dissociative Tendencies. Child Maltreat, 8, 302-318.

Byrne, M., \& Flood, B. (2003). Assessing the Teaching Quality of Accounting Programmes: An evaluation of the Course Experience Questionnaire. Assessment \& Evaluation in Higher Education, 28, 135-145. 
Campbell-Sills, L., Cohan, S. L., \& Stein, M. B. (2006). Relationship of resilience to personality, coping, and psychiatric symptoms in young adults. Behaviour Research and Therapy, 44, 585-599.

Carver, C. S., Scheier, M. F., \& Weintraub, J. K. (1989). Assessing coping strategies: A theoretically based approach. Journal of Personality and Social Psychology, 56, 267283.

Chambel, M. J., \& Curral, L. (2005). Stress in Academic Life: Work Characteristics as Predictors of Student Well-being and Performance. Applied Psychology, 54, 135-147.

Clauss-Ehlers, C. S. (2008). Sociocultural factors, resilience, and coping: Support for a culturally sensitive measure of resilience. Journal of Applied Developmental Psychology, 29, 197-212.

Connor, K. M., \& Davidson, J. R. T. (2003). Development of a new resilience scale: The Connor-Davidson Resilience Scale (CD-RISC). Depress. Anxiety, 18, 76-82.

Dao, T. K., Lee, D., \& Chang, H. L. (2007). Acculturation level, perceived English fluency, perceived social support level, and depression among Taiwanese international students. College Student Journal, 41, 287-295.

Dolbier, C. L., Jaggars, S. S., \& Steinhardt, M. A. (2010). Stress-related growth: preintervention correlates and change following a resilience intervention. Stress and Health, 26, 135-147.

Doll, B., \& Lyon, M. A., (1998). Risk and resilience: Implications for the delivery of educational and mental health services in schools. School Psychology Review, 27, 348-363.

Folkman, S. (2008). The case for positive emotions in the stress process. Anxiety, Stress \& Coping: An International Journal, 21, 3-14. 
Folkman, S., \& Lazarus, R. S. (1980). An analysis of coping in a middle-aged community sample. Journal of Health and Social Behavior, 21, 219-39.

Folkman, S., \& Moskowitz, J. T. (2004). Coping: Pitfalls and Promise. Annual Review of Psychology, 55, 745-774.

Fornell, C., \& Larcker, D. F. (1981). Evaluating Structural Equation Models with Unobservable Variables and Measurement Error. Journal of Marketing Research, 18, $39-50$.

Fredrickson, B.L. (1998). What good are positive emotions? Review of General Psychology, $2,300-319$.

Fredrickson, B.L. (2001). The role of positive emotions in positive psychology: The broadenand-build theory of positive emotions. American Psychologist, 56, 218-226.

Fredrickson, B. L., Tugade, M. M., Waugh, C. E., \& Larkin, G. R. (2003). What Good Are Positive Emotions in Crises? A Prospective Study of Resilience and Emotions Following the Terrorist Attacks on the United States on September 11th, 2001. Journal of Personality \& Social Psychology, 84, 365-376.

Grant, L., \& Kinman, G. (2012). Enhancing Wellbeing in Social Work Students: Building Resilience in the Next Generation. Social Work Education, 31, 605-621.

Hirsch, J. K., \& Ellis, J. B. (1996). Differences in life stress and reasons for living among college suicide ideators and non-ideators. College Student Journal, 30, 377-384.

Hu, L., \& Bentler, P. M. (1999). Cutoff criteria for fit indexes in covariance structure analysis: Conventional criteria versus new alternatives. Structural Equation Modeling: Multidisciplinary Journal, 6, 1-55.

Jöreskog, K. G., \& Sörbom, D. (1993). LISREL 8: Structural equation modeling with the SIMPLIS command language. Chicago: Scientific Software International 
Kline, R. B. (2011). Principles and Practice of Structural Equation Modeling. The Guilford Press; 3rd Edition.

Kwok, O. M., Hughes, J. N., \& Wen, L. (2007). Role of resilient personality on lower achieving first grade students' current and future achievement. Journal of School Psychology, 45, 61-82.

Lazarus, R. S., \& Folkman, S. (1984). Stress, appraisal, and coping. New York: Springer Publishing.

Leary, K. A., \& DeRosier, M. E. (2012). Factors Promoting Positive Adaptation and Resilience during the Transition to College. Psychology, 3, 1215-1222.

Leipold, B., \& Greve, W. (2009). Resilience. European Psychologist, 14, 40-50. doi:10.1027/1016-9040.14.1.40

Luthans, F., Avey, J. B., Smith, R. C. \& Li, W. (2008). More evidence on the value of Chinese workers' psychological capital: A potentially unlimited competitive resource? The International Journal of Human Resource Management, 19, 818-827.

Luthans, F., Youssef, C. M., Sweetman, D. S., \& Harms, P. D. (2013). Meeting the Leadership Challenge of Employee Well-Being Through Relationship PsyCap and Health PsyCap. Journal of Leadership \& Organizational Studies, 20, 118-133.

Luthar, S. S. (1991). Vulnerability and Resilience: A Study of High-Risk Adolescents. Child Development, 62, 600-616.

Luthar, S. S., Cicchetti, D., \& Becker, B. (2000). The Construct of Resilience: A Critical Evaluation and Guidelines for Future Work. Child Development, 71, 543-562.

MacCallum, R. C., Browne, M. W., \& Sugawara, H. M. (1996). Power analysis and determination of sample size for covariance structure modeling. Psychological Methods, 2, 130-149. 
MacCann, C., Fogarty, G. J., Zeidner, M., \& Roberts, R. D. (2011). Coping mediates the relationship between emotional intelligence (EI) and academic achievement. Contemporary Educational Psychology, 36, 60-70.

Martin, A. J., \& Marsh, H. W. (2006). Academic resilience and its psychological and educational correlates: A construct validity approach. Psychology in the Schools, 43, $267-281$.

McDonald, A. S. (2001) The Prevalence and Effects of Test Anxiety in School Children. Educational Psychology, 21, 89-101.

Midgley, C., Maehr, M. L., Hruda, L. Z., Anderman, E., Anderman, L., Freeman, K. E., Gheen, M., Kaplan, A., Kumar, R., Middleton, M. J., Nelso, J., Roeser, R., \& Urdan, T. (2000). Manual for Patterns of Adaptive Learning Scales. University of Michigan Press.

Muthén, L. K., \& Muthén, B. O. (2002). How to Use a Monte Carlo Study to Decide on Sample Size and Determine Power. Structural Equation Modeling: A Multidisciplinary Journal, 9, 599-620.

Ouweneel, E., Schaufeli, W. B., \& Le Blanc, P. M. (2013). Believe, and you will achieve: Changes over time in self-efficacy, engagement, and performance. Applied Psychology: Health and Well-Being, 5, 225-247.

Perczek, R., Carver, C. S., Price, A. A., \& Pozo-Kaderman, C. (2000). Coping, Mood, and Aspects of Personality in Spanish Translation and Evidence of Convergence With English Versions. Journal of Personality Assessment, 74, 63-87.

Podsakoff, P. M., MacKenzie, S. B., Lee, J. Y., \& Podsakoff, N. P. (2003). Common Method Biases in Behavioral Research: A Critical Review of the Literature and Recommended Remedies. Journal of Applied Psychology, 88, 879-903. 
Podsakoff, P. M., MacKenzie, S. B., \& Podsakoff, N. P. (2012). Sources of Method Bias in Social Science Research and Recommendations on How to Control It. Annual Review of Psychology, 63, 539-569.

Putwain, D. (2007). Researching academic stress and anxiety in students: some methodological considerations. British Educational Research Journal, 33, 207-219.

Richardson, M., Abraham, C., \& Bond, R. (2012). Psychological correlates of university students' academic performance: A systematic review and meta-analysis. Psychological Bulletin, 138, 353-387.

Riolli, L. (2012). Psychological Capital as a Buffer to Student Stress. Psychology, 3, 1202 1207.

Ryan, A. M. (2001). The peer group as a context for the development of young adolescents' motivation and achievement. Child Development, 72, 1135-1150.

Roddenberry, A., \& Renk, K. (2010). Locus of Control and Self-Efficacy: Potential Mediators of Stress, Illness, and Utilization of Health Services in College Students. Child Psychiatry \& Human Development, 41, 353-370.

Rode, J. C., Arthaud-Day, M. L., Mooney, C. H., Near, J. P., Baldwin, T. T., Bommer, W. H., \& Rubin, R. S. (2005). Life Satisfaction and Student Performance. Academy of Management Learning \& Education, 4, 421-433.

Ross, S. E., Niebling, B. C., \& Heckett, T. M. (1999). Sources of stress among college students. College Student Journal, 33, 316-318.

Salanova, M., Bresó, E., \& Schaufeli, W. B. (2005). Hacia un modelo espiral de las creencias de eficacia en el estudio del burnout y del engagement [Towards a spiral model of efficacy beliefs on the burnout and engagement research]. Ansiedad y Estrés, 11, 215231. 
Salanova, M., Schaufeli, W., Martínez, I., \& Bresó, E. (2010). How obstacles and facilitators predict academic performance: the mediating role of study burnout and engagement. Anxiety, Stress \& Coping, 23, 53-70.

Seligman, M. (2003) Authentic Happiness: Using the New Positive Psychology to Realize Your Potential for Deep Fulfilment. Nicholas Brealey, London.

Smith, B. W., Dalen, J., Wiggins, K., Tooley, E., Christopher, P., \& Bernard, J. (2008). The brief resilience scale: Assessing the ability to bounce back. International Journal of Behavioral Medicine, 15, 194-200.

Snyder, C. R., Shorey, H. S., Cheavens, J., Pulvers, K. M., Adams, V. H., \& Wiklund, C. (2002). Hope and academic success in college. Journal of Educational Psychology, $94,820-826$.

Spector, P. E. (2006). Method Variance in Organizational Research: Truth or Urban Legend? Organizational Research Methods, 9, 221-232.

Stallman, H. M. (2010). Psychological distress in university students: A comparison with general population data. Australian Psychologist, 45, 249-257.

Steinhardt, M., \& Dolbier, C. (2008). Evaluation of a Resilience Intervention to Enhance Coping Strategies and Protective Factors and Decrease Symptomatology. Journal of American College Health, 56, 445-453.

Struthers, C. W., \& Perry, R. P. (1996). Attributional style, attributional retraining, and inoculation against motivational deficits. Social Psychology of Education, 1, 171-187.

Suldo, S. M., Shaunessy, E., Michalowski, J., \& Shaffer, E. J. (2008). Coping strategies of high school students in an International Baccalaureate program. Psychology in the Schools, 45, 960-977. 
Tugade, M. M., \& Fredrickson, B. L. (2004). Resilient Individuals Use Positive Emotions to Bounce Back From Negative Emotional Experiences. Journal of Personality and Social Psychology, 86, 320.

Vandewalle, D. (1997). Development and Validation of a Work Domain Goal Orientation Instrument. Educational and Psychological Measurement, 57, 995-1015.

Vedhara, K., \& Nott, K.H. (1996). Psychosocial vulnerability to stress: A study of HIVpositive homosexual men. Journal of Psychosomatic Research, 41, 255-267.

Xanthopoulou, D., Bakker, A. B., Demerouti, E., \& Schaufeli, W. B. (2009). Reciprocal relationships between job resources, personal resources, and work engagement. Journal of Vocational Behavior, 74, 235-244.

Zautra, A. J. (2003). Emotions, stress, and health. New York: Oxford University Press. 
Table 1

Results of principal axis factoring analyses: standardized factor loadings of lower-order coping strategies on higher-order factors $(N=780)$

\begin{tabular}{lcccc}
\hline & \multicolumn{3}{c}{ Higher-order Factors } \\
\cline { 2 - 5 } & Problem- & Social & Avoidance & \\
Lower-order coping strategies & solving & & & acceptance \\
\hline Active coping & .811 & & & \\
Planning & .550 & & & \\
Emotional support & & .873 & & \\
Venting & & .606 & & \\
Instrumental support & & .655 & .561 \\
Disengagement & & & .540 \\
Denial & & & \\
Positive Reframing & & & \\
Humor & & & \\
Acceptance & & & \\
\hline
\end{tabular}


Table 2

Correlations for the study variables $(N=780)$

\begin{tabular}{lccccccc}
\hline & 1 & 2 & 3 & 4 & 5 & 6 & 7 \\
\hline 1. Social coping & $(.81)$ & & & & & \\
2. Problem-solving coping & -.06 & $(.68)$ & & & & \\
3. Positive acceptance coping & -.04 & $-.11^{* *}$ & $(.69)$ & & & \\
4. Avoidance coping & $-.08^{*}$ & $.10^{* *}$ & -.03 & $(.69)$ & & \\
5. Academic resilience & $-.26^{* *}$ & $.16^{* *}$ & $.33^{* *}$ & $-.14^{* *}$ & $(.89)$ & \\
6. Academic satisfaction & .01 & $.20^{* *}$ & .01 & $-.08^{*}$ & $.16^{* *}$ & $(.72)$ \\
7. Academic performance & $.12^{* *}$ & $.12^{* *}$ & -.06 & $-.10^{* *}$ & .03 & $.14^{* *}$
\end{tabular}

Notes: Cronbach's $\alpha$ reliability estimates are listed in the diagonal in parentheses.

$* p<.05 ; * * p<.01$ 


\section{Figure Captions}

Figure 1. The final model with standardized path coefficients $(N=780)$. 
Figure 1

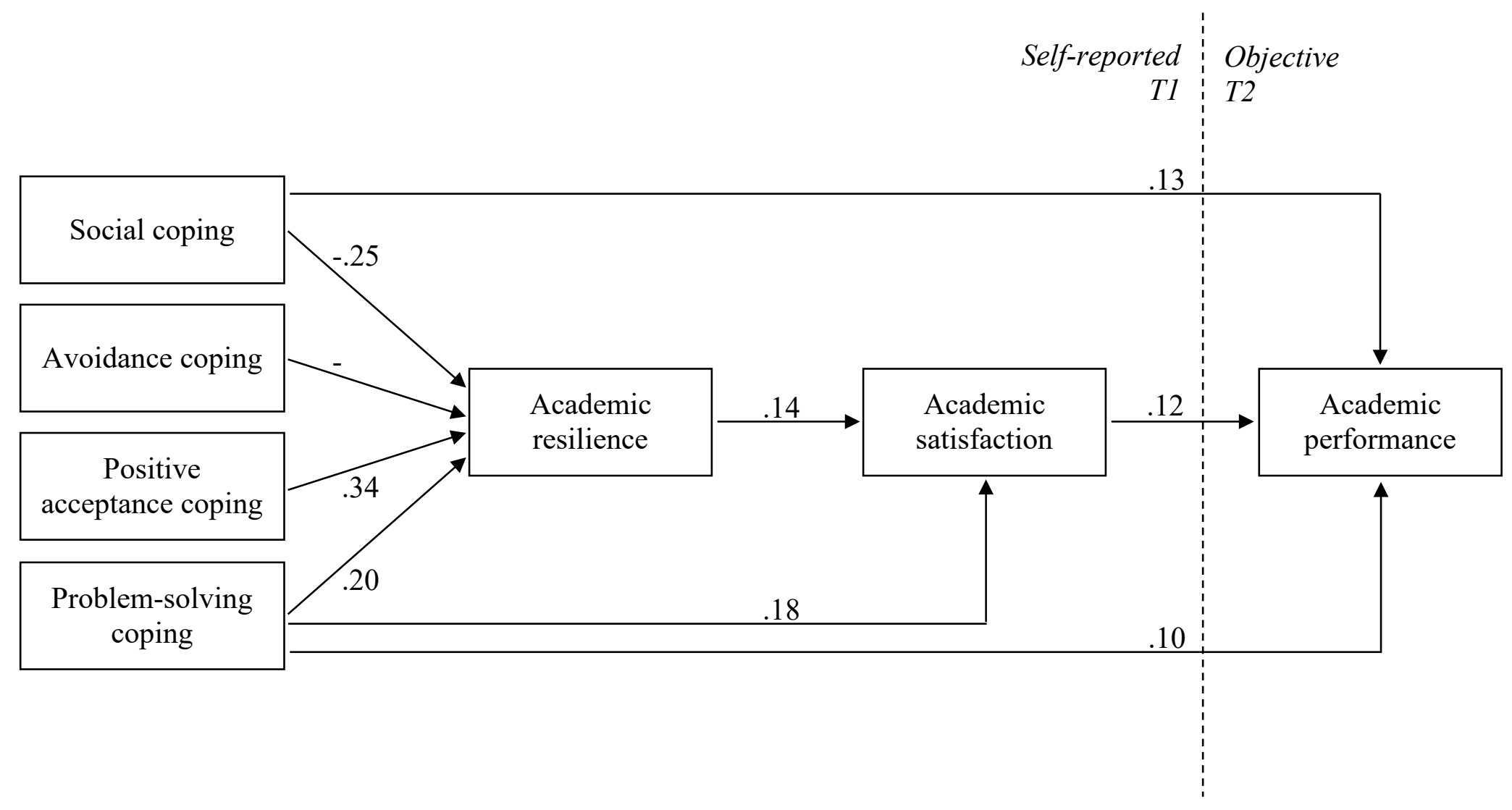

